\title{
The Infectious Bronchitis Coronavirus Envelope Protein Alters Golgi pH To Protect the Spike Protein and Promote the Release of Infectious Virus
}

\author{
Jason W. Westerbeck, ${ }^{\text {a* }}$ Carolyn E. Machamera \\ aDepartment of Cell Biology, The Johns Hopkins University School of Medicine, Baltimore, Maryland, USA
}

ABSTRACT Coronaviruses (CoVs) assemble by budding into the lumen of the early Golgi complex prior to exocytosis. The small CoV envelope (E) protein plays roles in assembly, virion release, and pathogenesis. CoV E has a single hydrophobic domain (HD), is targeted to Golgi membranes, and has cation channel activity in vitro. The E protein from avian infectious bronchitis virus (IBV) has dramatic effects on the secretory system, which require residues in the HD. Mutation of the HD of IBV E in a recombinant virus background results in impaired growth kinetics, impaired release of infectious virions, accumulation of IBV spike (S) protein on the plasma membrane compared to wild-type (WT) IBV-infected cells, and aberrant cleavage of IBV S on virions. We previously reported the formation of two distinct oligomeric pools of IBV $E$ in transfected and infected cells. Disruption of the secretory pathway by IBV E correlates with a form that is likely monomeric, suggesting that the effects on the secretory pathway are independent of E ion channel activity. Here, we present evidence suggesting that the monomeric form of IBV E correlates with an increased Golgi luminal $\mathrm{pH}$. Infection with IBV or expression of IBV E induces neutralization of Golgi $\mathrm{pH}$, promoting a model in which IBV E alters the secretory pathway through interaction with host cell factors, protecting IBV S from premature cleavage and leading to the efficient release of infectious virus from the cells. This is the first demonstration of a coronavirus-induced alteration in the microenvironment of the secretory pathway.

IMPORTANCE Coronaviruses are important human pathogens with significant zoonotic potential. Progress has been made toward identifying potential vaccine candidates for highly pathogenic human CoVs, including the use of attenuated viruses that lack the CoV E protein or express E mutants. However, no approved vaccines or antiviral therapeutics exist. Understanding the role of the CoV E protein in virus assembly and release is thus an important prerequisite for potential vaccines as well as in identifying novel antiviral therapeutics.

KEYWORDS Golgi, coronavirus, E protein, oligomers, pH, viroporin

Cover he majority of human coronaviruses (CoVs) cause mild disease phenotypes. However, when novel coronaviruses like severe acute respiratory syndrome CoV (SARS$\mathrm{CoV}$ ) and Middle East respiratory syndrome CoV (MERS-CoV) emerge from their animal reservoirs to infect humans (1), they elicit a robust and aberrant immune response that can lead to a very serious and deadly pneumonia (2). Importantly, there are no effective vaccines or therapeutics to treat these CoVs. Efforts to develop long-term therapeutic strategies to combat novel, highly pathogenic CoVs will be aided by an increased understanding of conserved viral mechanisms at the level of their cell and molecular biology.

One of the more fascinating and enigmatic aspects of CoV biology is that CoV virions

Citation Westerbeck JW, Machamer CE. 2019. The infectious bronchitis coronavirus envelope protein alters Golgi pH to protect the spike protein and promote the release of infectious virus. J Virol 93:e00015-19. https://doi.org/10 .1128/JVI.00015-19.

Editor Tom Gallagher, Loyola University Chicago

Copyright $\odot 2019$ American Society for Microbiology. All Rights Reserved.

Address correspondence to Carolyn E.

Machamer, machamer@jhmi.edu.

* Present address: Jason W. Westerbeck, W. Harry Feinstone Department of Molecular Microbiology and Immunology, The Johns Hopkins Bloomberg School of Public Health, Baltimore, Maryland, USA.

Received 3 January 2019

Accepted 7 March 2019

Accepted manuscript posted online 13

March 2019

Published 15 May 2019 
bud into the lumen of the secretory pathway at the endoplasmic reticulum-Golgi intermediate compartment (ERGIC) and then must navigate through the Golgi complex and the anterograde endomembrane system to be efficiently released from the host cell (3). The structure and function of the Golgi complex depend upon an acidic $\mathrm{pH}$ gradient that decreases from the lumen of the cis-Golgi to the lumen of the trans-Golgi network (TGN). This pH gradient is produced by a balance maintained by proton influx into the lumen of the Golgi complex, proton leak, and counterion conductance (4). Pharmacological and other manipulations of the $\mathrm{pH}$ gradient that result in neutralization of the lumen have all been shown to cause slow trafficking of cargo through the Golgi complex as well as alteration in Golgi morphology (4-7). A class of small viral membrane proteins with ion channel activity, called viroporins (8), has been shown to have dramatic effects on the secretory pathway, similar to those elicited by pharmacological manipulation of luminal $\mathrm{pH}$. Several well-studied members of this viroporin family of proteins include the influenza A virus (IAV) $M 2$ protein, the hepatitis $C$ virus (HCV) p7 protein, and the CoV envelope (E) protein. These representative viroporins demonstrate several common functional features despite differences in viral assembly and budding locations. It has been suggested that the role of $\mathrm{M} 2$ in the secretory pathway is to neutralize luminal $\mathrm{pH}$ to protect the hemagglutinin (HA) fusion protein of influenza from premature activation (9-11). Overexpression of M2 causes secretory pathway disruption where the rate of intracellular trafficking is slowed and Golgi morphology is altered (5). HCV p7 is also thought to play a protective role by allowing egress of viral structural proteins through the secretory pathway. HCV lacking active p7 can be partially rescued by both pharmacological neutralization of the luminal spaces by bafilomycin $A 1$ and in trans expression of IAV $M 2(12,13)$. Similar to $M 2$, the infectious bronchitis virus (IBV) coronavirus $E$ protein elicits multiple secretory pathway disruption phenotypes when overexpressed in mammalian cells (14).

To understand CoV E at a cell biological level, a recombinant virus system was used to replace the hydrophobic domain (HD) of IBV E with the HD of the vesicular stomatitis virus glycoprotein (VSV G), and the recombinant virus was called IBV EG3 $(14,15)$. Replacing the HD of IBV E with a heterologous sequence of the same length does not impair Golgi targeting or interaction with IBV M during assembly $(16,17)$ but would be expected to impair ion channel function. One-step growth curves revealed that IBV EG3 grew to a titer 10-fold lower than that of wild-type (WT) IBV in infected Vero cells. At late times postinfection, the majority of infectious virus resides in the supernatant surrounding WT IBV-infected cells, while the majority of infectious IBV EG3 is intracelIular (15). Vero cells infected with IBV EG3 accumulate more IBV spike (S) protein on the plasma membrane than WT IBV-infected cells, and this accumulation of IBV S leads to increases in the size and rate of formation of virus-induced syncytia (15). Highly purified virions from IBV EG3-infected cells lack a full complement of spikes, and most $S$ is cleaved near the virion envelope, likely explaining the reduced infectivity of released particles (14). A buildup of vacuole-like compartments containing virions as well as other aberrant material in IBV EG3-infected cells may explain the damage to $S(14,15)$.

Intriguingly, when WT IBV E is transiently overexpressed in HeLa cells, the Golgi complex completely disassembles, while the Golgi complex in cells overexpressing IBV EG3 is intact (15). This observation suggested that IBV E alters the secretory pathway of the host cell. Expression of IBV E or EG3 reduces rates of trafficking of both membrane and secretory cargo (15). Given that the release of infectious IBV EG3 is reduced, it was surprising that wild-type $E$ protein reduced cargo trafficking. We hypothesized that since the HD was required for these phenotypes, alteration of the Golgi lumen by $E$ ion channel activity was required for maintaining intact virus, and the reduced rates of trafficking were an acceptable compromise for the virus (18).

Studies probing the nature of CoV E ion channel activity have centered on understanding the residues required for this activity and the associated pathogenic and cell biological phenotypes elicited by different CoV E proteins. Two residues in the HD of SARS-CoV E, N15 and V25, have been shown to promote viral fitness during infection $(19,20)$. Mutation of N15 or V25 abolishes ion channel activity of SARS-CoV E in artificial 
membranes $(19,20)$. We previously reported that the E protein of IBV expressed in mammalian cells is found in two pools by velocity gradient analysis: a low-molecularweight (LMW) pool and a high-molecular-weight (HMW) pool (21). The LMW pool represents IBV E in a monomeric state, while the HMW pool correlates with a homooligomer of IBV E. When mutations corresponding to the conserved HD residues of SARS-CoV $E$ that inhibit ion channel activity are made in IBV E (T16A and A26F), the HD mutants segregate primarily into one oligomeric pool or the other. The $E^{T 16 A}$ mutant is primarily in the HMW pool, while the $\mathrm{E}^{\mathrm{A} 26 \mathrm{~F}}$ mutant is primarily in the LMW pool. The presence of the LMW pool of IBV E, the predominant and likely monomeric form found when $\mathrm{E}^{\mathrm{A} 26 \mathrm{~F}}$ is present, correlates with the secretory pathway disruption associated with the WT IBV E protein (21). This was surprising in that it suggested an E ion-channelindependent role for IBV E associated with manipulation of the secretory pathway. It was recently reported that that these HD mutants abolish ion channel activity of IBV E in artificial membranes, and virus titers are reduced by a log in the supernatant of infected cells, suggesting a defect in virion release (22). Our data on the IBV EG3 corroborate data from that study (15).

Here, we provide evidence for the neutralization of Golgi luminal $\mathrm{pH}$ during IBV infection, and we demonstrate that transient overexpression of the IBV E protein, but not HD mutants deficient in the LMW pool of IBV E, is sufficient to cause a significant increase in the $\mathrm{pH}$ of the Golgi lumen. We suggest that increased trafficking and altered cleavage of the IBV S protein observed during IBV EG3 infection may reflect the detrimental effect of normal Golgi $\mathrm{pH}$ on IBV $\mathrm{S}$ processing. We demonstrate that IBV $\mathrm{S}$ processing and trafficking are similarly aberrant when coexpressed with $\mathrm{EG} 3$ or $\mathrm{E}^{\mathrm{T} 16 \mathrm{~A}}$ but not WT E or EA26F and that IAV M2 can substitute for WT E to protect $S$ from premature cleavage. Our results describe the first demonstration of a coronavirusmediated alternation of the luminal microenvironment of the secretory pathway.

(This article was submitted to an online preprint archive [23].)

\section{RESULTS}

IBV S is aberrantly processed in EG3 virions. The IBV S protein is cleaved by a furin-like protease generating the $\mathrm{S} 1$ and $\mathrm{S} 2$ subunits during trafficking through the Golgi complex and at a second site (S2') that primes the protein for fusion with the host cell (24). The S protein of the mutant virus with an HD replacement in the E protein (IBV EG3) is subject to further proteolysis near the junction of the protein with the viral envelope, resulting in a C-terminal fragment that we term the "stub" (Fig. 1A) (14). To compare the processing of the $S$ protein in virions from cells infected with WT IBV and IBV EG3, supernatants from cells infected for $18 \mathrm{~h}$ at a multiplicity of infection (MOI) of 0.05 were clarified, and virions were enriched by spinning through a $20 \%$ sucrose cushion. The pellets were subjected to SDS-PAGE, and immunoblots were probed with a monoclonal antibody that recognizes S1 (3C7B8) (25) and a polyclonal antibody raised to the $C$ terminus of $S$ that detects $S 2$ fragments, including the stub (26). As shown in Fig. $1 B$ and C, EG3 virions have significantly less S1 than do WT virions, with an increased fraction of a fragment that runs at about $65 \mathrm{kDa}$. EG3 virions also have reduced S2 and increased S2' and stub compared to WT virions. We previously reported that nearly all of the S in purified EG3 virions was cleaved to the stub (14). We believe that the additional cleavage in the purified virus occurred during isolation, as multiple steps (including two sucrose gradients) were performed in the absence of protease inhibitors, unlike the enrichment procedure described here. These results suggest that IBV EG3 encounters cellular proteases more readily than WT virus or that the S protein undergoes a conformational change that is more conducive to processing during trafficking of virions.

IBV induces an increase in Golgi luminal pH during infection. One possible explanation for the aberrant processing of $S$ in IBV EG3-infected cells is that the microenvironment of the secretory pathway is altered when the E viroporin activity is normal $(15,18,21)$ but is unaltered in IBV EG3-infected cells. Given that the effects of IBV E overexpression on the Golgi complex are similar to those in cells where the 
A

S2'

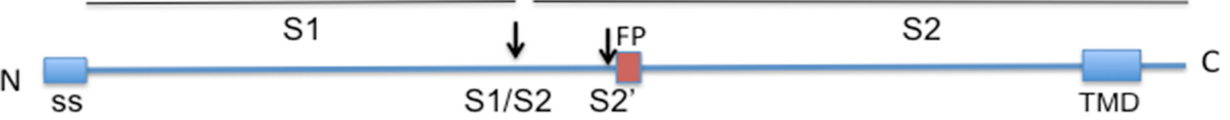

B

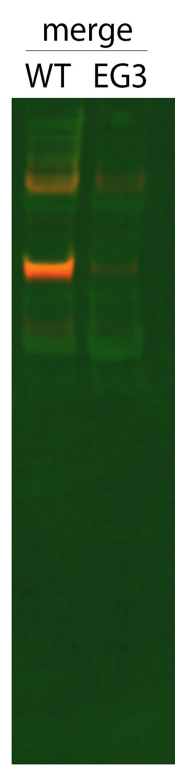

$\mathrm{S} 1 \mathrm{Ab}$

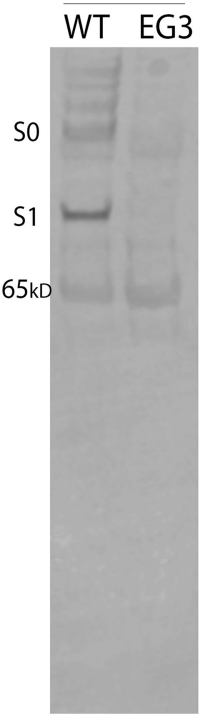

C

\section{$\mathrm{S} 2 \mathrm{Ab}$}

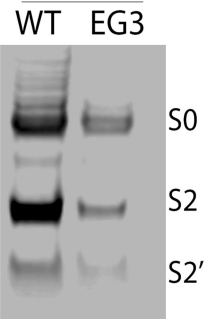

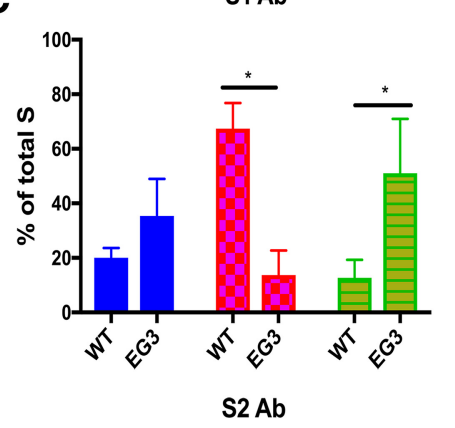

$\mathrm{S1} \mathrm{Ab}$

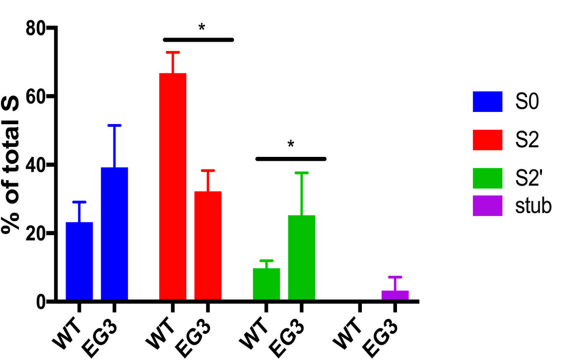

FIG 1 The IBV S protein is aberrantly processed in virions from IBV EG3-infected cells. (A) Cartoon of IBV Beaudette $\mathrm{S}$ showing the cleavage sites. The signal sequence (ss), fusion peptide (FP), and transmembrane domain (TMD) are indicated. (B) Representative blot of virions purified from the supernatants of WT IBV- or IBV EG3-infected Vero cells by concentration through a sucrose cushion. Pellets were electrophoresed on NuPAGE 4-to-12\% gradient gels and after transfer to PVDF membranes were probed with mouse anti-S1 and rabbit anti-S2, followed by IRDye $800 \mathrm{CW}$ donkey anti-mouse IgG and IRDye $680 \mathrm{CW}$ donkey anti-rabbit IgG. The left panel is a merge of the $800-\mathrm{nm}$ and $680-\mathrm{nm}$ wavelengths of the Li-Cor image showing that S1 and S2 essentially comigrate on these gradient gels. The middle and right panels show the signal for the S1-specific mouse monoclonal 3C7B8 and the rabbit anti-S C terminus antibodies $(A b)$, respectively. The cleavage products are indicated, as are the positions of the molecular weight markers (in kilodaltons). (C) Quantification showing the fraction of total S for each S1 fragment (top graph) or S2 fragment (bottom graph). Error bars indicate standard deviations (SD) ( $n=4$ [S2 antibody] or 3 [S1 antibody]). A paired $t$ test was performed in GraphPad Prism, with a $P$ value of $<0.05\left(^{*}\right)$ where indicated. All other pairs were not statistically significant.

luminal $\mathrm{pH}$ is neutralized $(4,6,7)$, we measured the luminal $\mathrm{pH}$ of the Golgi complex in IBV-infected Vero cells. We used flow cytometric analysis of a ratiometric pHluorin molecule targeted to the Golgi lumen with a reporter consisting of the green fluorescent protein (GFP) pHluorin molecule fused to the membrane-targeting sequence of the trans-Golgi network-resident protein TGN38 (6). We chose to use the trans-Golgi network pHluorin molecule because the TGN is the most acidic compartment of the Golgi complex, and thus, any alteration in $\mathrm{pH}$ would likely be most detectable in this compartment. We generated a clonal Vero cell line that stably expressed pHluorinTGN38 (Fig. 2A). The generation of this cell line allowed us to ensure that all infected cells were expressing pHluorin-TGN38. The cells were treated with cycloheximide for 60 min to chase newly synthesized TGN38-pHluorin from the endoplasmic reticulum (ER). To generate a pH calibration curve, uninfected cells were subjected to treatment with buffers ranging from pH 5.5 to 7.5 in the presence of the ionophores monensin and nigericin prior to flow analysis. The emission ratios of the biphasic $\mathrm{pH}$-sensitive pHluorin at these known $\mathrm{pH}$ values can then be used to construct a standard curve (Fig. 2B) and predict the Golgi luminal $\mathrm{pH}$ in cells infected with IBV in buffer at physiological $\mathrm{pH}$ and lacking ionophores (Fig. $2 \mathrm{C}$ ). Infection resulted in a robust increase in the Golgi luminal $\mathrm{pH}$ (Fig. 2D and E). 
A

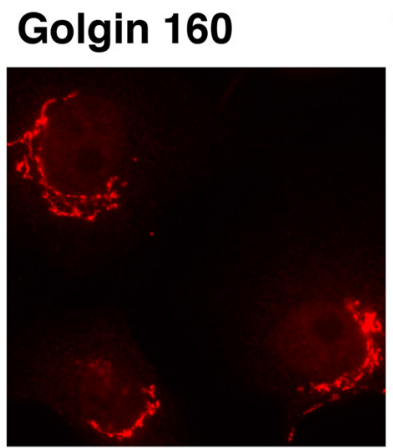

TGN38-pHluorin

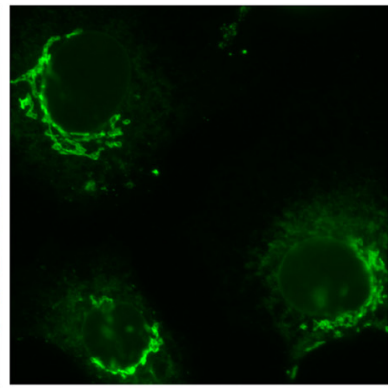

B

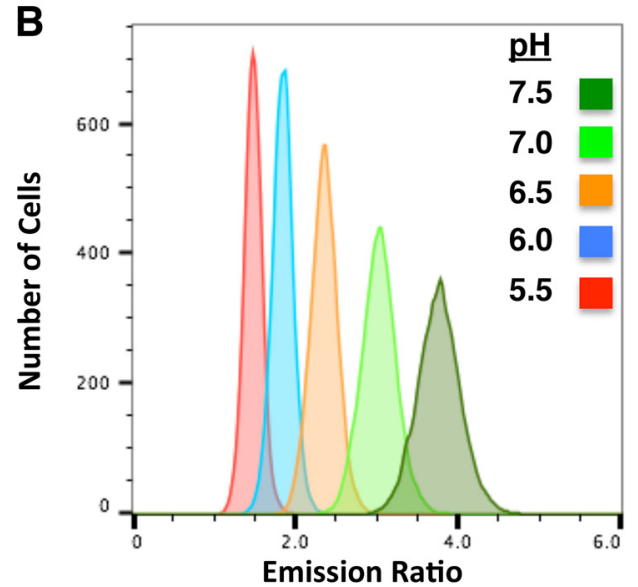

D

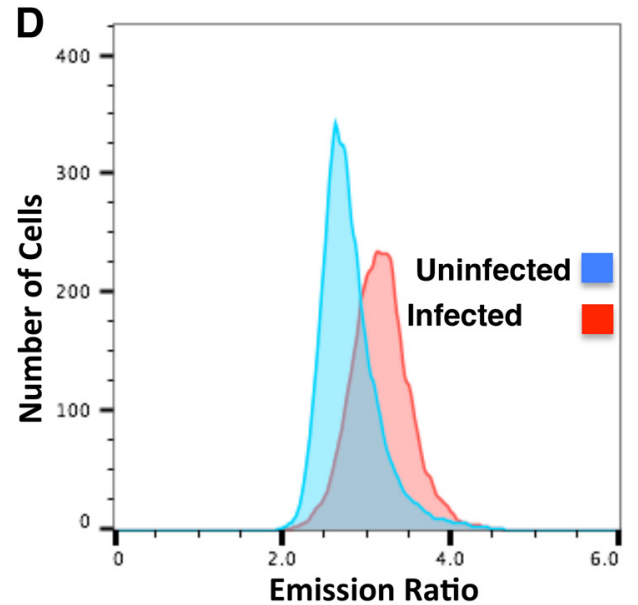

C

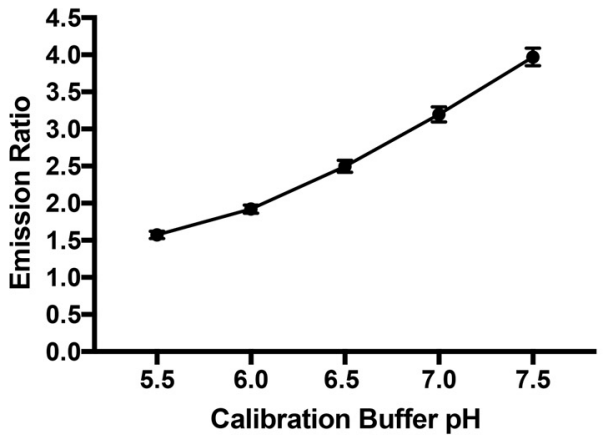

E

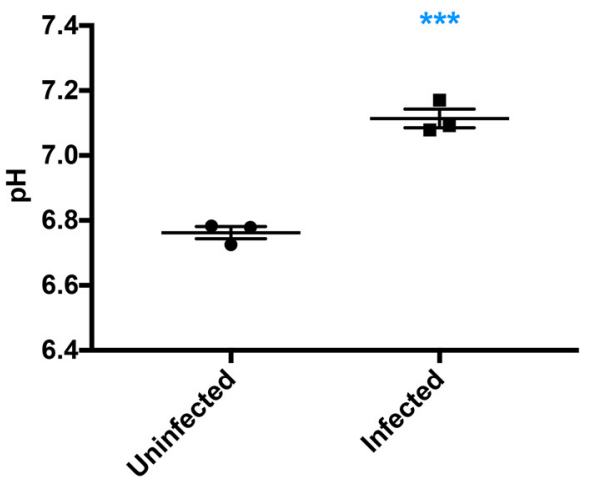

FIG 2 IBV infection alters Golgi pH. (A) Vero cells stably expressing pHluorin-TGN38 were evaluated by indirect immunofluorescence microscopy. Cells were labeled with rabbit anti-golgin-160 and mouse anti-GFP, followed by Alexa 546-conjugated anti-rabbit IgG and Alexa 488-conjugated anti-mouse IgG. (B) Vero cells stably expressing pHluorinTGN38 were used to assess the $\mathrm{pH}$ of the trans-Golgi network by determining the ratio of the $\mathrm{pH}$-sensitive dual-emission spectrum by flow cytometry. The cells were in buffers of known $\mathrm{pH}$ and contained ionophores to equilibrate the extracellular and luminal $\mathrm{pH}$ of the Golgi membrane. Data from a representative flow cytometry experiment are graphed. (C) Calibration curves were generated from data like those illustrated in panel B, in order to calculate the $\mathrm{pH}$ of cells infected with IBV or uninfected cells. The calibration curve pictured was derived from data from 3 independent experiments ( $\sim 10,000$ cells each). Error bars indicate standard errors of the means (SEM). (D) Cell emission ratios for Vero cells infected or mock infected with IBV and stably expressing pHluorin-TGN38 from a representative experiment. (E) Average calculated $\mathrm{pH}$ values from 3 independent experiments $(\sim 10,000$ cells each). Unpaired $t$ tests were performed in Prism at $99 \%$ confidence, with an assumption of equal variance. ${ }^{* * *}, P<0.001$. Error bars indicate SEM.

We attempted to measure the Golgi luminal pH in cells infected with IBV EG3 but were unable to achieve a high percentage of infected cells in the absence of syncytium formation, since this virus is not efficiently released and spreads best by cell-cell fusion. We found that syncytia were fragile, and this precluded flow cytometric analysis. 

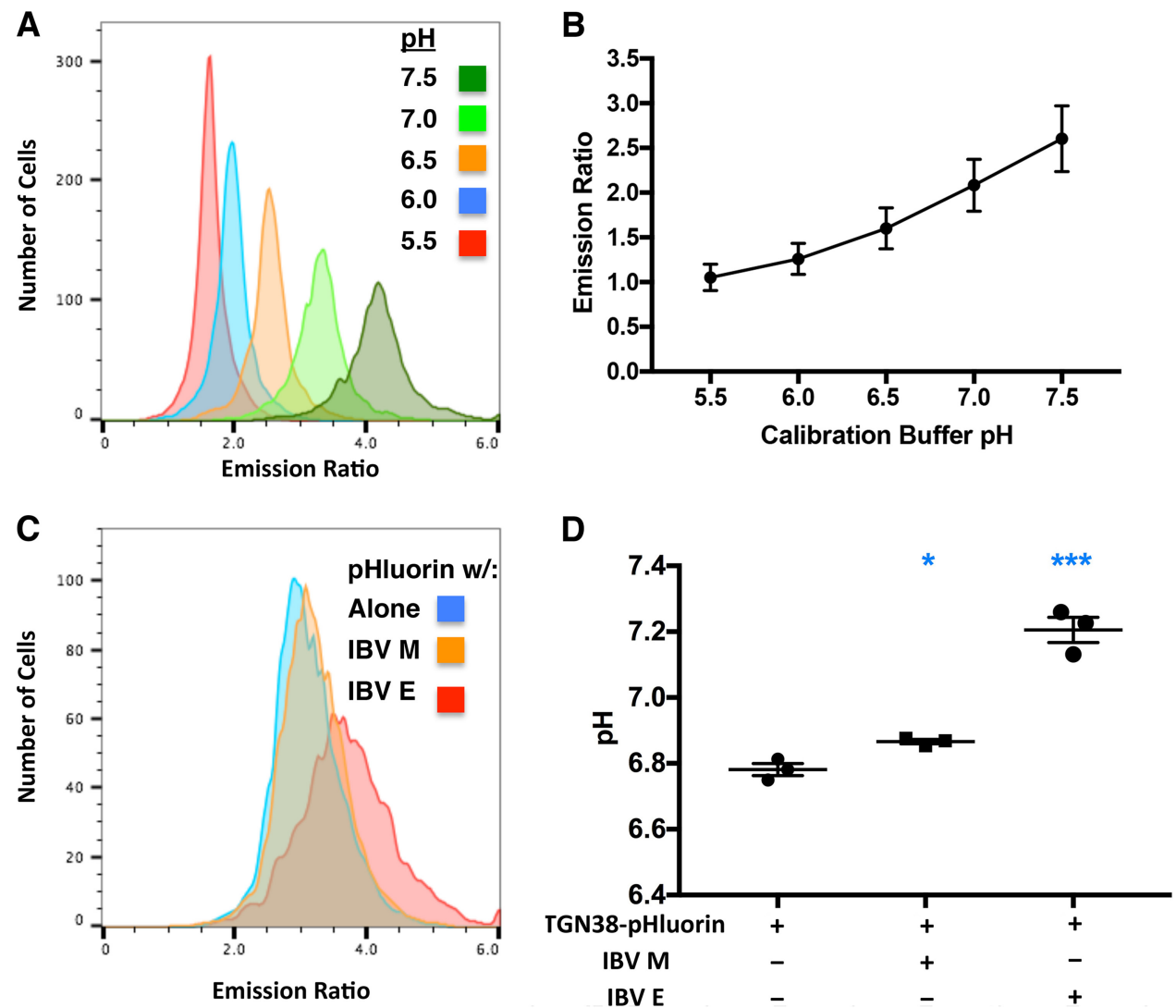

FIG 3 Overexpression of IBV E alters Golgi pH. (A) The trans-Golgi pH in HeLa cells transiently expressing pHluorin-TGN38 was assessed by determining the ratio of the $\mathrm{pH}$-sensitive dual-emission spectrum by flow cytometry. The cells were in buffers of known $\mathrm{pH}$ and contained ionophores to equilibrate the extracellular and luminal $\mathrm{pH}$ of the Golgi membrane. Data from a representative flow cytometry experiment are graphed. (B) Calibration curves were generated from data like those illustrated in panel $\mathrm{A}$, in order to calculate the $\mathrm{pH}$ of cells expressing pHluorin-TGN38 alone or in combination with IBV E or E mutants. The calibration curve pictured was derived from data from 7 independent experiments ( $~ 5,000$ cells each). Error bars indicate SEM. (C) Cell emission ratios for HeLa cells expressing pHluorin-TGN38 alone and with IBV E or IBV M (control) from a representative experiment. (D) Average calculated $\mathrm{pH}$ values from 3 independent experiments ( 5,000 cells each). Unpaired $t$ tests were performed in Prism at $99 \%$ confidence, with an assumption of equal variance. ${ }^{*}, P<0.05 ;{ }^{* *}, P<0.001$. Error bars indicate SEM.

Instead, we turned to transfected cells to determine if the E protein could neutralize the Golgi lumen.

Overexpression of the IBV E protein increases the $\mathbf{p H}$ of the Golgi lumen. To determine if the $\mathrm{E}$ protein was responsible for the $\mathrm{pH}$ change, HeLa cells were cotransfected with a plasmid encoding IBV E along with pHluorin-TGN38 or with pHluorin-TGN38 alone. We used transient transfection of the reporter here to ensure that the pHluorin-expressing cells were also expressing the E protein and used HeLa cells for their ease of transfection. In separate cells, we included a plasmid encoding IBV $M$ (as another overexpressed Golgi membrane protein) as a control. As described above, transfected cells were pretreated with cycloheximide for $60 \mathrm{~min}$ to chase newly synthesized proteins out of the ER. A standard curve in cells expressing pHlorin-TGN38 alone was produced in cells treated with ionophores in calibrated $\mathrm{pH}$ buffers (Fig. 3A and B), as described above. As shown in Fig. 3 C and D, IBV E robustly neutralized the trans-Golgi luminal $\mathrm{pH}$ when overexpressed in HeLa cells, whereas overexpression of the IBV M protein did not.

The increase in Golgi pH correlates with the LMW pool of IBV E. To determine the role of IBV E oligomerization and, by inference, viroporin activity in the alteration of Golgi luminal $\mathrm{pH}$, we analyzed two HD point mutants of IBV E that segregate into different oligomeric states. Our previous findings suggest that IBV $E^{A 26 F}$ is found 


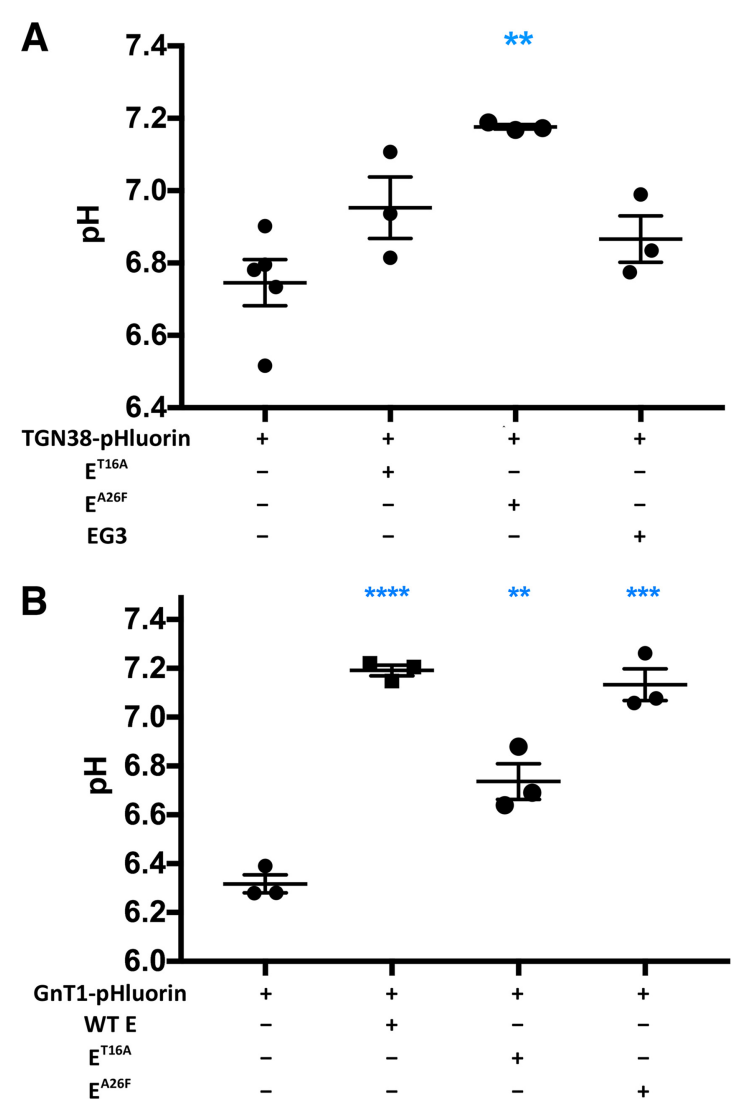

FIG 4 Change in Golgi pH correlates with the LMW HD mutant of IBV E. (A) HeLa cells transiently expressing pHluorin-TGN38 alone or with IBV E or HD mutants were evaluated by flow cytometry, and the average calculated $\mathrm{pH}$ values from 3 independent experiments are graphed ( $\sim 5,000$ cells each). (B) HeLa cells transiently expressing medial-Golgi-tagged pHluorin, GnT1-pHluorin, with IBV E or HD mutants were evaluated by flow cytometry, and the average calculated $\mathrm{pH}$ values from 3 independent experiments are graphed ( $\sim 5,000$ cells each). Unpaired $t$ tests were performed in Prism at $99 \%$ confidence, with an assumption of equal variance. ${ }^{* *}, P<0.01 ;{ }^{* * *}, P<0.001 ;{ }^{* * *}, P<0.0001$. Error bars indicate SEM.

predominantly in the LMW, likely monomeric, form and that IBV $E^{T 16 A}$ is found predominantly in the HMW, higher-order oligomer (21). In addition, we analyzed the EG3 mutant of IBV E, with a complete HD replacement. Both IBV E'16A and IBV EG3 had trans-Golgi pH measurements similar to those of the IBV $M$ membrane protein control ( $\mathrm{pH} 6.95$ and $\mathrm{pH} 6.87$, respectively), while IBV EA26F elicited a $\mathrm{pH}$ increase similar to that of the wild-type IBV E protein (pH 7.18) (Fig. 4A). This suggested that the LMW pool of IBV E correlates with the luminal pH increase of the Golgi complex in addition to the secretory pathway disruption demonstrated in our previous work (15, $18,21)$. The same experiment was performed with a medial-Golgi-tagged pHluorin, GnT1 ( $N$-acetylglucosaminyltransferase I)-pHluorin, to assess if the alteration in pH was specific to the TGN. Here, a standard curve was generated from cells expressing GnT2-pHlorin alone. Expression of either IBV E or IBV EA26F elicited a robust pH increase (Fig. 4B). Interestingly, IBV $\mathrm{E}^{\mathrm{T} 16 \mathrm{~A}}$ increased the $\mathrm{pH}$ significantly although not as robustly as IBV E and IBV EA26F. We found that the $\mathrm{pH}$ of the trans-Golgi network (measured with pHluorin-TGN38) was higher than that of the medial-Golgi (measured with GnT1pHluorin). This was unexpected and is addressed in Discussion. We previously reported that the T16A mutant was not completely inactive in Golgi disruption (21), and the better dynamic range of the medial-Golgi pHluorin is likely the reason why we were able to measure a significant increase at the medial-Golgi but not in the TGN. Altogether, the results in transfected cells implicate the monomeric form of IBV E in neutralization of the Golgi lumen during infection and transfection. 
Attempts to rescue IBV EG3 by manipulation of Golgi pH. Despite intense efforts, we were unable to conclusively determine whether an increase in Golgi pH could rescue the deficiencies of IBV EG3. We used two different methods to neutralize acidic compartments: drugs (bafilomycin A1, monensin, or ammonium chloride) and overexpression of influenza A virus $\mathrm{M} 2$, a pH-activated proton channel. However, the drugs inhibited exocytosis at all concentrations used (during short or long infections), including release of virus. For IAV M2 transfection, we were unable to obtain a high percentage of transfected cells that were subsequently infected with IBV EG3. In several experiments where the percentage of transfected and infected cells was greater than $40 \%$, we obtained $40 \%$ to $75 \%$ increases in the release of infectious IBV EG3, but most experiments failed to show a reasonable overlap of transfection and infection and rescue of IBV EG3 infectivity (data not shown). Additionally, attempts to make stable lines expressing M2 and pHluorin-TGN38 did not yield lines expressing M2 at a level high enough to alter Golgi luminal $\mathrm{pH}$. We thus turned to another approach to assess the role of neutralization of the Golgi membrane by IBV E.

Expression of IAV M2 decreases the total amounts of IBV $\mathbf{S}$ at the cell surface and the cleaved S species in cells. We predicted that neutralization of Golgi pH by IBV E during infection protects the IBV S protein from premature proteolysis at the normal acidic $\mathrm{pH}$ of the trans-Golgi network. We also predicted that processing and trafficking of IBV $\mathrm{S}$ in the presence of a protein that can alter pH (i.e., IBV E or IAV M2) would be similar, while one deficient in this (IBV EG3 or $\mathrm{E}^{\mathrm{T} 16 \mathrm{~A}}$ ) would produce premature cleavage and more IBV $S$ at the surface of cells. To test these predictions, we first demonstrated that when transiently overexpressed in Vero cells, IAV M2 neutralized the trans-Golgi network in our pHluorin/flow cytometry assay in the absence of the M2 inhibitor amantadine but not in the presence of $5 \mu \mathrm{M}$ amantadine, as expected (Fig. 5A and B) $(5,9-11)$. With proof of principle established for $\mathrm{M} 2 \mathrm{pH}$ alteration during transfection, cells were cotransfected with plasmids encoding IBV S and IBV E, or IBV EG3, with or without the IAV M2 protein. Surface biotinylation was performed, and the level of IBV $S$ at the cell surface after streptavidin pulldown was determined by Western blot analysis (Fig. 5C). As predicted, there was a significant increase in the total amount of IBV $\mathrm{S}$ at the surface of EG3-expressing cells compared to cells expressing WT IBV E. Notably, the presence of M2 in EG3-expressing cells reduced the amount IBV $S$ at the surface of cells compared to cells transfected with the empty vector (Fig. 5D). We also measured the total amounts of cleaved IBV S species (S2, S2', and stub) in transfected cell lysates (without surface biotinylation). We analyzed only S2 fragments, since most of the $\mathrm{S}$ in transfected cells is S0, and the S1-specific monoclonal antibody signal was too weak to detect S1 and smaller fragments in this assay. The levels of S2 and stub in EG3-expressing cells were significantly reduced when $M 2$ was coexpressed, with an increase in S0 similar to levels in WT E-expressing cells (Fig. 6A and B). Importantly, aberrant processing of IBV $S$ in cells cotransfected with the empty vector or IBV $E^{\mathrm{T} 16 \mathrm{~A}}$ could be abrogated by expression of IAV M2 (Fig. 6C and D). On the other hand, the presence of M2 had no effect on IBV S processing in cells expressing WT IBV E or IBV EA26F, and cells expressing these IBV E constructs always had less S2 and undetectable levels of the stub. These results suggest that neutralizing Golgi luminal $\mathrm{pH}$ could indeed reduce trafficking of IBV $S$ to the plasma membrane and protect it from premature cleavage.

\section{DISCUSSION}

Neutralization of the Golgi complex by IBV E. Our flow cytometry and pHsensitive ratiometric analyses demonstrated that the Golgi luminal $\mathrm{pH}$ is increased in IBV-infected cells. Overexpression of IBV E caused a similar increase in the $\mathrm{pH}$ of the lumen of the trans-Golgi network and also increased the $\mathrm{pH}$ of the medial-Golgi. Our baseline measurement of $\mathrm{pH} 6.78$ in the context of transient overexpression of TGN38pHluorin and IBV E protein in HeLa cells (Fig. 3D) and the baseline of pH 6.76 in the context of Vero cells stably expressing TGN38-pHluorin (Fig. 2E) are both similar to, although somewhat higher than, $\mathrm{pH}$ values reported in the literature for the TGN. 
A. MERGE M2 TGN38-pHluorin

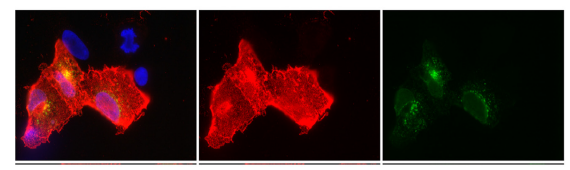

C.
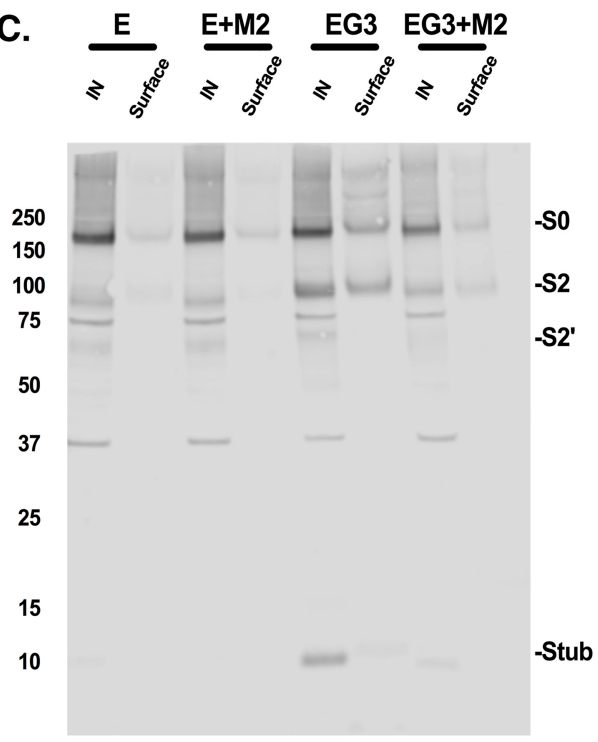

B.

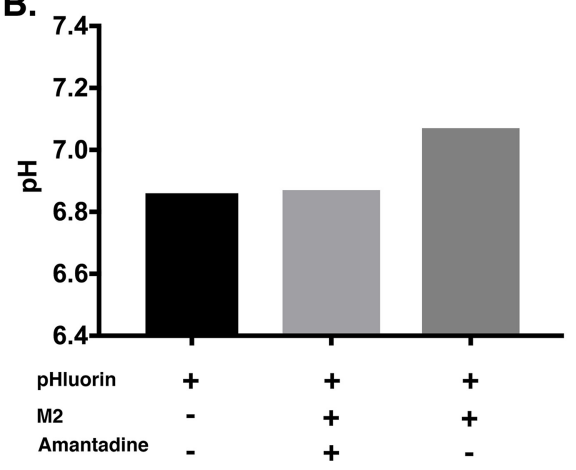

D.

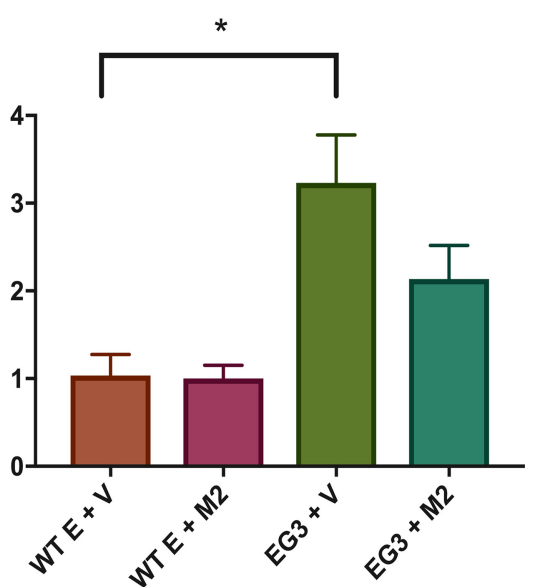

FIG 5 Influenza A virus M2 alters Golgi pH and reduces IBV S at the surface of EG3-expressing cells. (A) Vero cells expressing pHluorin-TGN38 and M2 were evaluated by indirect immunofluorescence microscopy. Cells were labeled with rabbit anti-GFP and mouse anti-M2, followed by Alexa 488-conjugated anti-rabbit IgG and Alexa 546-conjugated anti-mouse IgG, and Hoechst stain. Some M2 is present in the Golgi region. (B) Vero cells transiently expressing pHluorin-TGN38 with or without transient expression of IAV M2 and with or without treatment with amantadine $(5 \mu \mathrm{M})$ were evaluated by flow cytometry. The calculated $\mathrm{pH}$ values from a single independent experiment are graphed ( $\sim 5,000$ cells each). (C) Representative blot from Vero cells expressing IBV $S$ with either WT IBV E or EG3, along with either the empty vector or IAV M2, after surface biotinylation. Biotinylated proteins were isolated with streptavidin-agarose beads from lysates. Both the input (IN) $(10 \%)$ and surface fractions (100\%) were subjected to Western blot analysis with rabbit anti-IBV $\mathrm{S}_{\mathrm{CT}}$ followed by IRDye 680CW donkey anti-rabbit IgG. The positions of the IBV S2 species are indicated, as are the molecular weight markers in kilodaltons. (D) Quantification of the total IBV $S$ at the cell surface from 3 experiments. The low percentage of surface $S$ is likely due to inefficient biotinylation. One-way analysis of variance (ANOVA) was performed with GraphPad Prism. ${ }^{*}, P<0.05$ compared to WT E plus the vector. Error bars indicate SD.

Values for the $\mathrm{pH}$ reported by pHluorin-TGN38 in different cell types range from $\mathrm{pH} 6.2$ to $6.7(6,27,28)$. We believe that the higher baseline measurement that we observed is likely due to some plasma membrane cycling of pHluorin-TGN38, which would increase the average $\mathrm{pH}$ in a given cell, since the $\mathrm{pH}$ of the extracellular buffer was $\mathrm{pH}$ 7.3. The cycling of pHluorin-TGN38 is likely to be the predominant reason for a higher-than-expected TGN pH, since the medial-Golgi pHluorin reported a $\mathrm{pH}$ of $\sim 6.4$ (Fig. 4B). We believe that the consistent shift in the Golgi $\mathrm{pH}$ in cells expressing IBV $\mathrm{E}$ is more important than the actual baseline $\mathrm{pH}$ value that we observed with pHlorinTGN38. Previously, the TGN38-pHluorin construct was used to demonstrate that CHO cells lacking the counterion channel Golgi pH regulator (GPHR) had a 0.4-pH-unit increase (6), which substantiates the magnitude of the observed $\mathrm{pH}$ increase in this study.

Neutralization of Golgi luminal pH correlates with secretory pathway disruption and the LMW pool of IBV E. Our analysis of the HD mutants of IBV E demonstrated that neutralization of the TGN induced by overexpression of wild-type IBV E correlates with the presence of the LMW, likely monomeric, pool of IBV E, which is the 
A

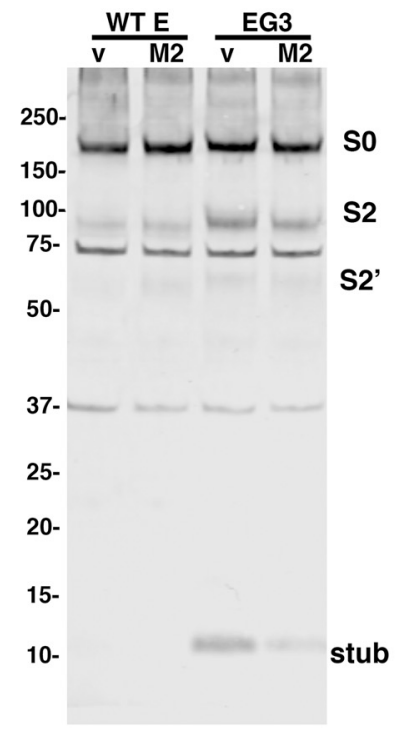

C

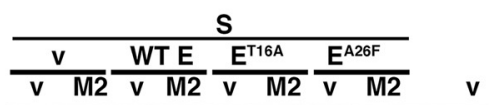

IBV S2

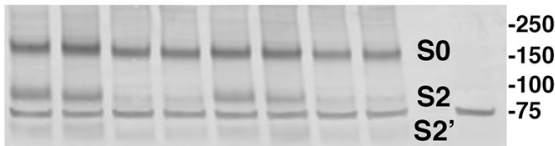

IBV E

IAV M2

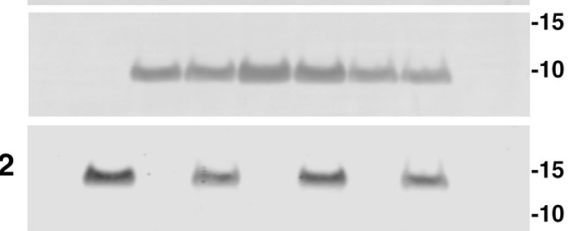

B

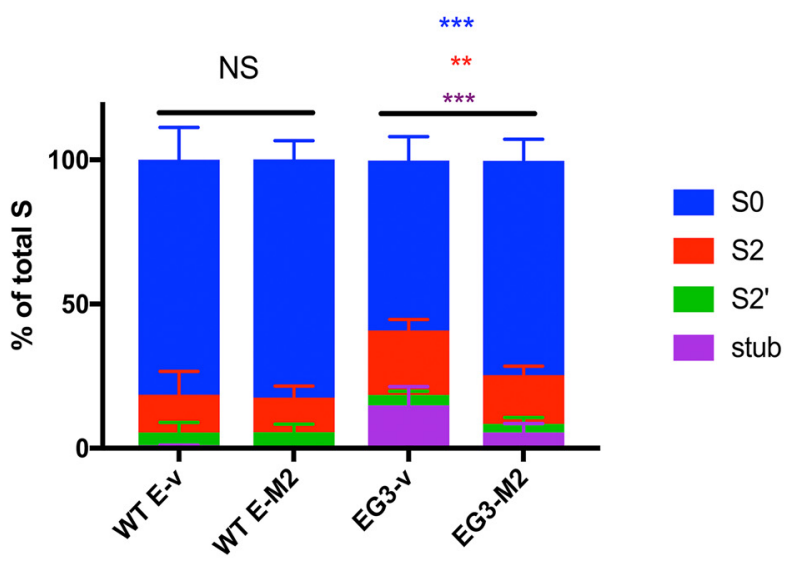

D

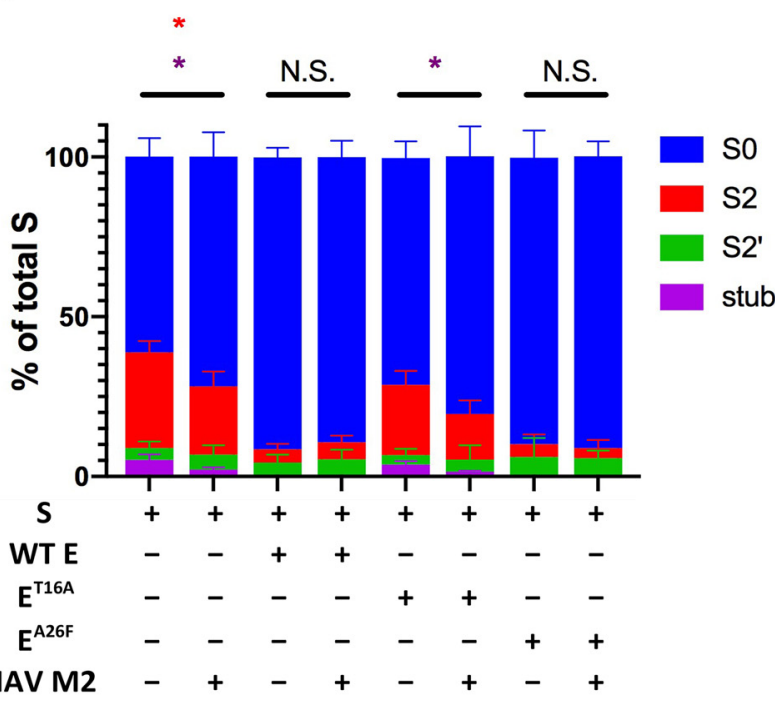

FIG 6 Expression of IAV M2 corrects aberrant processing of IBV S. (A) Representative blot from Vero cells expressing IBV S with either WT IBV E or EG3, along with either the empty vector or IAV M2, showing the S2-containing fragments and the positions of the molecular weight markers (in kilodaltons). Expression levels of E and EG3 were similar by blotting, as were those of M2 in the relevant samples (not shown). (B) Quantification of data from 7 experiments indicating the fraction of each S2 form. Error bars indicate SD. (C) Representative blot from Vero cells expressing IBV S alone or with WT IBV E, IBV E ${ }^{16 A}$, or IBV EA26F, along with either the empty vector or IAV M2, showing the S2-containing fragments and the positions of the molecular weight markers (in kilodaltons). The far-right lane is a sample from cells transfected with the vector alone to indicate the background with the anti- $S_{C T}$ antibody. (D) Quantification of data from 3 experiments indicating the fraction of each S2 form. For both graphs, unpaired $t$ tests were performed with GraphPad Prism between the empty vector and IAV M2-expressing samples for each set (NS, not significant; ${ }^{*}, P<0.05 ;{ }^{* *}, P<0.01 ;{ }^{* *}, P<0.005$ ), with colors representing the relevant $P$ value.

predominant form of the protein observed in cells expressing the IBV EA26F mutant (Fig. 4). The IBV EA26F mutant elicited a $\mathrm{pH}$ shift slightly higher than the increase observed with the WT IBV E protein. However, the IBV ET16A or IBV EG3 HD mutant did not cause a statistically significant $\mathrm{pH}$ shift in the trans-Golgi lumen. We previously showed that the LMW pool of IBV E correlates with secretory pathway disruption (21), including Golgi disassembly and slow trafficking of model cargo proteins, observed when the wild-type IBV E protein is expressed $(15,18)$. We hypothesized that the Golgi disruption was likely occurring in an IBV E ion-channel-independent manner (21). This study corroborates our hypothesis and suggests that the monomeric form of IBV E causes Golgi disruption via alteration of Golgi luminal pH through a mechanism involving 
interaction with a host protein. This interpretation is strengthened by evidence demonstrating that neither the IBV E E $16 \mathrm{~A}$ nor the IBV E ${ }^{\mathrm{A} 26 \mathrm{~F}}$ mutant has ion channel activity in artificial membranes (22), suggesting that any remaining HMW, oligomeric IBV E that may be present when IBV EA26F is expressed is not likely eliciting secretory pathway disruption or $\mathrm{pH}$ neutralization via IBV E ion channel activity. However, To et al. recently reported that mutation of IBV E at T16 but not A26 prevents oligomerization of IBV E, the opposite of our findings (22). The difference in these results is likely due to different modes of protein expression and the downstream assays used to evaluate oligomerization. In our studies, we expressed the HD mutants in mammalian cells and evaluated oligomerization via velocity sucrose gradient analysis followed by cross-linking and immunoprecipitation of gradient fractions of interest (21). To et al. bacterially expressed these proteins and then analyzed them via native PAGE after purifying and resolubilizing the samples (22).

Neutralization of Golgi luminal pH by IBV E and IAV M2 correlates with reduced cleavage of IBV S protein. A current model for the cleavage and function of CoV $\mathrm{S}$ proteins suggests that proteolytic processing at two cleavage sites (S1/S2 and S2') releases the protein from its prefusion conformation and allows exposure of the fusion peptide $(29,30)$. This change in conformation may also release the $\mathrm{S} 1$ subunits from the S2 subunits of the CoV S trimer (29). A possible detrimental consequence of the normal acidic Golgi $\mathrm{pH}$ for the virus could be that the $\mathrm{S}$ protein is subject to a conformational change and premature, and possibly excessive, proteolytic processing, resulting in the release of the S1 subunit prior to receptor binding. This would result in noninfectious or impaired virions. Indeed, the level of S1 in EG3 virions is lower than in WT virions, compared to the level of total S2 (Fig. 1B). Our data also indicate that when IBV $S$ is expressed in cells alone or in the presence of EG3 or IBV $E^{T 16 A}$, the levels of IBV $S$ cleavage species are increased significantly compared to those of IBV $S$ in the presence of IBV E, IBV EA26F, or IAV M2, lending support to the hypothesis that the neutralization of Golgi pH by IBV E protects IBV S from premature cleavage (Fig. 6). Additionally, when overexpressed in cells with EG3, S is present to a greater extent at the cell surface than when expressed with WT E (Fig. 5D), corroborating previous data observed during IBV EG3 infection (15).

CoV E protein viroporins and host protein interaction. The finding that IBV E modifies the luminal microenvironment to promote infectious virus production indicates similarities to IAV M2 and HCV p7. What is strikingly different about IBV E, however, is that this protein is likely causing secretory pathway disruption in an IBV E ion-channel-independent way. If IBV E were acting as a monomer to elicit secretory pathway disruption and alter $\mathrm{pH}$, interaction of IBV $\mathrm{E}$ with a host protein(s) would be necessary.

Evidence suggests that CoV E proteins interact with host cell proteins to influence pathogenicity (31). Interaction of SARS-CoV E with the PDZ (postsynaptic density protein 95/discs Large/zonula occludens 1) domain-containing scaffolding protein syntenin and with the tight junction protein PALS1 (protein associated with Lin Seven 1) through its PBM (PDZ-binding motif) domain implicates the $E$ protein as a pathogenic determinant (32-34). Our study suggests that the transmembrane domain of IBV E might interact with a transmembrane host protein to induce a $\mathrm{pH}$ increase in the Golgi lumen (e.g., by altering the activity of the viral ATPase [vATPase], the proton leak channel, or a channel that relieves membrane potential [4]). It is also possible that the relatively long cytoplasmic tail of IBV E interacts with a host protein to modify the secretory pathway. In this case, alterations in the HD could lead to structural changes in the cytoplasmic tail that impact such interactions.

SARS-CoV $3 a$ and $8 a$ proteins have been shown to have ion channel activity in artificial membranes, in addition to E $(32,35-37)$. Intriguingly, the SARS-CoV 3a protein elicits inflammatory signaling similar to that of the SARS-CoV E protein, suggesting that CoVs may encode accessory proteins that (i) may overlap in function to the E protein or (ii) may substitute for a particular role of the multifunctional IBV E protein. Addi- 
tionally, the SARS-CoV 3a protein has been shown to induce Golgi fragmentation as an antagonist of the Arf1 GTPase involved in maintaining the structure and function of the Golgi complex (38). Further study of these SARS-CoV viroporins outside the complicated context of infection, especially their ability to induce $\mathrm{pH}$ changes in the lumen of the secretory pathway, will inform our studies on the IBV E protein.

Our results are the first demonstration that the luminal microenvironment of the Golgi membrane is altered by coronavirus infection. While other viral viroporins (e.g., IAV M2 and HCV p7) have been shown to alter the luminal microenvironment, IBV E appears to do so by a mechanism that does not involve its ion channel activity. Whether the role of the putative IBV E-interacting protein(s) is $\mathrm{pH}$ maintenance, vesicle formation, membrane architecture, protein glycosylation, or any number of jobs performed by constituents of the secretory pathway, interaction of the protein(s) or lipid(s) with the large amount of IBV E known to reside at the ERGIC could disrupt the pH directly or indirectly by interfering with normal secretion or architecture of the Golgi complex. In summary, studies addressing CoV E protein-protein and protein-lipid interactions, and the development of tools to evaluate ion channel activity in vivo, will go a long way in elucidating the precise mechanisms of the multifunctional family of viroporin proteins.

\section{MATERIALS AND METHODS}

Cell culture. HeLa and Vero cells were cultured in Dulbecco's modified Eagle medium (DMEM; Invitrogen/Gibco, Grand Island, NY) containing 10\% fetal bovine serum (FBS; Atlanta Biologicals, Lawrenceville, GA) and $0.1 \mathrm{mg} / \mathrm{ml}$ Normocin (InvivoGen, San Diego, CA) at $37^{\circ} \mathrm{C}$ under $5 \% \mathrm{CO}_{2}$.

Plasmids. The pCAGSS IBV E, IBV EG3, IBV M, IBV E $16 \mathrm{~A}$, IBV EA26F, codon-optimized IBV S, M2, and empty pCAGGS-MCS plasmids have been previously described (15, 18, 21, 39-41). The pCAGGS M2 plasmid was a generous gift from Andrew Pekosz. The pME-zeo-pHluorin-TGN38 plasmid and GnT1pHluorin plasmid have been previously described and were generous gifts from Yusuke Maeda (6).

Antibodies. The rabbit polyclonal antibodies recognizing the $\mathrm{C}$ terminus of IBV $\mathrm{E}$ and the $\mathrm{N}$-terminal head of golgin-160 have been previously described $(42,43)$. The antibody generated against the $C$ terminus of IBV S (anti-IBV $S_{C T}$ ) has also been previously described (26). The mouse monoclonal antibody recognizing IBV S1 was a gift from Ellen Collisson (25). The mouse monoclonal antibody recognizing the $\mathrm{N}$ terminus of influenza A virus M2 has been previously described and was a generous gift from Andrew Pekosz (44). The mouse anti-GFP antibody was obtained from Roche (Mannheim, Germany). The rabbit anti-GFP antibody was obtained from Thermo Fisher Scientific (Rockford, IL). Alexa Fluor 488-conjugated anti-rabbit lgG, Alexa Fluor 488-conjugated anti-mouse IgG, Alexa Fluor 568-conjugated anti-rabbit lgG, and Alexa Fluor 568-conjugated anti-mouse IgG were obtained from Invitrogen/Molecular Probes (Eugene, OR).

Transient transfection. X-tremeGENE 9 DNA transfection reagent (Roche, Indianapolis, IN) was used to transiently transfect cells according to the manufacturer's protocol. For the $\mathrm{pH}$ measurement experiments, subconfluent HeLa cells in 6-mm dishes were transfected with $1 \mu \mathrm{g}$ of each plasmid indicated for a particular experiment and diluted into Opti-MEM (Invitrogen/Gibco) with X-tremeGENE 9 at a 1:3 ratio. When the TGN38-pHluorin plasmid was transfected alone, the pCAGGS-MCS empty vector was transfected to control for the total amount of DNA transfected. For the cotransfection of IBV S with E, EG3, and IAV M2, subconfluent Vero cells in 6-well dishes were transfected with a total of $2 \mu \mathrm{g}$ of DNA: $1 \mu \mathrm{g}$ of pCAGGS/IBV S plus $0.5 \mu \mathrm{g}$ pCAGGS/IBV E or EG3 and $0.5 \mu \mathrm{g}$ pCAGGS/MCS or pCAGGS/IAV M2, as described above.

Establishment of a TGN38-pHluorin stable Vero cell line. Subconfluent Vero cells were transfected with the pME-zeo-pHluorin-TGN38 plasmid according to the manufacturer's protocol (X-tremeGENE 9). Transfected cells were grown in DMEM containing 10\% FBS under selection with zeocin (Invitrogen) at $250 \mu \mathrm{g} / \mathrm{ml}$. Individual clones were selected and evaluated by indirect immunofluorescence microscopy.

IBV S processing in virions. The Beaudette strain of recombinant IBV used in this study and the IBV EG3 mutant have been previously described $(14,45)$. Confluent Vero cells in 35-mm dishes were infected at an $\mathrm{MOI}$ of 0.05 with wild-type (WT) IBV or IBV EG3 for $18 \mathrm{~h}$. Supernatants $(2 \mathrm{ml})$ were mixed with a protease inhibitor cocktail (Sigma) and clarified by centrifugation at 4,000 rpm for $20 \mathrm{~min}$ at $4^{\circ} \mathrm{C}$. The clarified supernatant was overlaid onto a $1-\mathrm{ml}$ sucrose cushion $(20 \%$ sucrose in $0.15 \mathrm{M} \mathrm{NaCl}$ and $10 \mathrm{mM}$ HEPES [pH 7.2]) in TLA110 centrifuge tubes (Beckman). After spinning at 80,000 rpm for 60 min, pellets were resuspended in $20 \mu \mathrm{l}$ of $2 \times$ NuPAGE sample buffer containing $5 \% \beta$-mercaptoethanol and heated at $90^{\circ} \mathrm{C}$ for $5 \mathrm{~min}$. Samples were electrophoresed in NuPAGE 4\%-to-12\% gradient gels (Thermo Fisher) and transferred to a low-fluorescence polyvinylidene difluoride (PVDF) membrane (Millipore). After blocking in $10 \mathrm{mM}$ Tris- $\mathrm{HCl}$ (pH 7.4)- $0.15 \mathrm{M} \mathrm{NaCl}$ (Tris-buffered saline [TBS]) plus $5 \%$ nonfat milk, membranes were probed with a mouse monoclonal antibody (3C7B8) for 2 to 3 days at $4^{\circ} \mathrm{C}$ to detect S1-containing fragments. After rinsing in TBS-0.05\% Tween 20 (TBST), S2-containing fragments were detected with rabbit anti-IBV $S_{C T}(26)$ diluted 1:3,000 in TBST-milk for $1 \mathrm{~h}$ at room temperature (RT). Secondary antibodies were IRDye 800CW donkey anti-mouse IgG and IRDye 680CW donkey anti-rabbit IgG (both from Li-Cor), diluted 1:10,000 in TBST-milk. Blots were imaged using the Li-Cor Odyssey CLx 
system at 700- and 800-nm wavelengths. Quantification was performed with Image Studio (Li-Cor), and each IBV S fragment was expressed as a percentage of the total S. Statistical analysis was done with GraphPad Prism.

Indirect immunofluorescence microscopy. Cells were washed with phosphate-buffered saline (PBS) and fixed in $3 \%$ paraformaldehyde in PBS for $10 \mathrm{~min}$ at $22^{\circ} \mathrm{C}$. The fixative was quenched in PBS containing $10 \mathrm{mM}$ glycine (PBS-Gly), and the cells were permeabilized in $0.5 \%$ Triton X-100 in PBS-Gly for 3 min. The coverslips were washed twice with PBS-Gly and incubated with primary antibody in PBS-Gly with $1 \%$ bovine serum albumin (BSA) for $20 \mathrm{~min}$ at room temperature. Rabbit anti-IBV E and rabbit anti-golgin-160 were used at a 1:1,000 dilution. Rabbit anti-GFP and mouse anti-M2 were used at a 1:500 dilution. Mouse anti-GFP was used at a 1:300 dilution. The cells were then washed twice with PBS-Gly and incubated for 20 min with secondary antibody diluted in PBS-Gly with 1\% BSA. Alexa Fluor 488-conjugated anti-rabbit IgG and Alexa Fluor 568-conjugated anti-mouse IgG were used at a 1:1,000 dilution. The coverslips were washed twice in PBS-Gly, incubated with Hoechst $33285(0.1 \mu \mathrm{g} / \mathrm{ml})$ to stain DNA, rinsed twice in PBS-Gly, and mounted on slides in glycerol containing $0.1 \mathrm{M} \mathrm{N}$-propylgallate. Images were captured using an Axioskop microscope (Zeiss) equipped for epifluorescence with an Orca-03G charge-coupled-device camera (Hamamatsu, Japan) and iVision software (Bio Vision Technologies).

Determination of Golgi pH during IBV infection. Vero cells stably expressing TGN38-pHluorin, seeded on $6-\mathrm{cm}$ dishes at $3.5 \times 10^{5}$ cells, were inoculated with IBV diluted to an $\mathrm{MOI}$ of 25 in serum-free (SF) DMEM, and virus was adsorbed for $1 \mathrm{~h}$ with rocking. The inoculum was removed, and the cells were rinsed with DMEM containing 5\% FBS. The cells were then incubated at $37^{\circ} \mathrm{C}$ in DMEM containing $5 \%$ FBS for $18 \mathrm{~h}$. Cells were washed with PBS, trypsinized for $3 \mathrm{~min}$, and resuspended in ice-cold SF DMEM. Cells were centrifuged at $112 \times g$ and washed with ice-cold SF DMEM twice. Cells were centrifuged as described above and resuspended in $1 \mathrm{ml}$ of calibration buffers $\left(140 \mathrm{mM} \mathrm{KCl}, 2 \mathrm{mM} \mathrm{CaCl}, 1 \mathrm{mM} \mathrm{MgSO} \mathrm{M}_{4}\right.$ $1.5 \mathrm{mM} \mathrm{K}_{2} \mathrm{HPO}_{4}, 10 \mathrm{mM}$ glucose, $10 \mathrm{mM}$ MES [morpholineethanesulfonic acid], $10 \mathrm{mM} \mathrm{HEPES}, 10 \mu \mathrm{M}$ monensin, $10 \mu \mathrm{M}$ nigericin) of the specified $\mathrm{pH}$ to generate a calibration curve or Na-Ringer buffer ( $\mathrm{pH}$ 7.3) $\left(140 \mathrm{mM} \mathrm{NaCl}, 2 \mathrm{mM} \mathrm{CaCl} 2,1 \mathrm{mM} \mathrm{MgSO}{ }_{4}, 1.5 \mathrm{mM} \mathrm{K}_{2} \mathrm{HPO}_{4}, 10 \mathrm{mM}\right.$ glucose, $10 \mathrm{mM} \mathrm{MES,} 10 \mathrm{mM}$ HEPES) in the case of experimental samples. The cells were incubated at room temperature for $\sim 10 \mathrm{~min}$ before being run through an LSRII flow cytometer (Becton, Dickinson). pHluorin was excited at $405 \mathrm{~nm}$ and $488 \mathrm{~nm}$, and the emission signals were collected with detection filters at 500 to $550 \mathrm{~nm}$ and 515 to $545 \mathrm{~nm}$, respectively. Flow cytometric data were collected and quantified using FACSDiva 8.0 software. The emission ratios ( $405 \mathrm{~nm} / 488 \mathrm{~nm}$ ) of TGN38-pHluorin in calibration buffers of known $\mathrm{pH}$ were used to generate a linear calibration curve (Microsoft Excel) with which to calculate the luminal Golgi $\mathrm{pH}$ in infected and uninfected cells.

Transient expression of TGN38-pHluorin or GnT1-pHluorin and IBV E or HD mutants in HeLa cells. At $12 \mathrm{~h}$ posttransfection, HeLa cells transiently expressing WT or mutant IBV E and TGN38-pHluorin or GnT1-pHluorin; TGN38-pHluorin alone; or GnT1-pHluorin alone were washed with SF DMEM and incubated for $1 \mathrm{~h}$ at $37^{\circ} \mathrm{C}$ in SF DMEM containing $100 \mu \mathrm{g} / \mathrm{ml}$ cycloheximide. Cells were then washed with PBS, trypsinized for $3 \mathrm{~min}$, and resuspended in ice-cold SF DMEM. Cells were centrifuged at $112 \times g$ and washed with ice-cold SF DMEM twice. Cells were centrifuged as described above and resuspended in $1 \mathrm{ml}$ of the calibration buffers to generate the standard curve, as described above, or in buffer lacking the ionophores to determine the Golgi pH. IBV M, another viral membrane protein localized to the Golgi membrane, was used as a membrane protein overexpression control.

Surface biotinylation. At $24 \mathrm{~h}$ posttransfection, Vero cells, in 35-mm dishes, expressing IBV S with either WT IBV E or EG3, along with either empty vector or IAV M2, were incubated with $0.5 \mathrm{mg} / \mathrm{ml}$ EZ-link-NHS-SS-biotin (Pierce) in Hanks' buffered salt solution at $0^{\circ} \mathrm{C}$ for $30 \mathrm{~min}$. After quenching the biotin in PBS with $10 \mathrm{mM}$ glycine for $5 \mathrm{~min}$ at $0^{\circ} \mathrm{C}$, cells were rinsed in PBS, scraped into PBS, and pelleted at 4,000 rpm for $2.5 \mathrm{~min}$. After lysis in $60 \mu \mathrm{l}$ of a detergent solution ( $1 \% \mathrm{NP}-40,0.4 \%$ deoxycholate, $50 \mathrm{mM}$ Tris- $\mathrm{HCl}$ [pH 8.0], and $62.5 \mathrm{mM}$ EDTA plus a protease inhibitor cocktail) at $0^{\circ} \mathrm{C}$ for $20 \mathrm{~min}$, samples were clarified by spinning at $14,000 \mathrm{rpm}$ for $10 \mathrm{~min}$ at $4^{\circ} \mathrm{C}$. Ten percent $(6 \mu \mathrm{l})$ was removed for the "input" (and combined with $6 \mu \mathrm{l}$ of $2 \times$ sample buffer), and the remainder was diluted with $200 \mu \mathrm{l} \mathrm{NHN} \mathrm{(1 \%} \mathrm{NP-40,}$ $10 \mathrm{mM}$ HEPES [pH 7.2], $150 \mathrm{mM} \mathrm{NaCl}$ ). Streptavidin-agarose beads (50 $\mu$ l of a $50 \%$ slurry; Pierce) washed in NHN were added, and samples were incubated for $2 \mathrm{~h}$ at $4^{\circ} \mathrm{C}$ and for $30 \mathrm{~min}$ at $22^{\circ} \mathrm{C}$. The beads were washed twice in $\mathrm{NHN}$, eluted in $2 \times$ sample buffer, electrophoresed, and transferred to a PVDF membrane as described above. S2-containing fragments were detected with rabbit anti-S $\mathrm{S}_{\mathrm{CT}}$ and IRDye $680 \mathrm{CW}$ donkey anti-rabbit lgG and quantified as described above.

Assessment of IBV S proteolytic processing in transfected cells. Subconfluent Vero cells in 35-mm dishes were transfected with $1 \mu \mathrm{g}$ of a plasmid encoding IBV $\mathrm{S}$ alone or with $0.5 \mu \mathrm{g}$ of a plasmid encoding IBV E, EG3, T16A, or A26F, with or without $0.5 \mu \mathrm{g}$ of a plasmid encoding IAV M2, as described above. Total DNA for each transfection was adjusted to $2 \mu \mathrm{g}$ with the empty vector. Cells were lysed in $100 \mu \mathrm{l}$ of a detergent solution (as described above) at 21 to $24 \mathrm{~h}$ posttransfection. Approximately $15 \%$ of each sample was resolved by SDS-PAGE, transferred to a PVDF membrane, and blotted as described above. IBV S2 fragments were detected with anti-S $\mathrm{S}_{\mathrm{CT}}$. Equivalent samples were run on a separate gel to detect IBV E (rabbit anti-IBV E) and IAV M2 (mouse anti-M2).

\section{ACKNOWLEDGMENTS}

We thank Helene Verhije (Utrecht University) for plasmids used in the construction of the codon-optimized IBV S construct, Ellen Collison and Yvonne Drechsler (Western University of Health Sciences) for monoclonal anti-IBV S1, Yusuke Maeda (Osaka University) for the pHluorin-TGN38 and GnT1-pHluorin plasmids, and Andrew Pekosz (The 
Johns Hopkins Bloomberg School of Public Health) for the M2 expression construct and antibody. We also thank Tricia Nilles for help with flow cytometry and the past and present members of the Machamer laboratory for critical and helpful discussions about the data presented here.

This work was supported by NIH grants R01 GM117399 and T32 GM007445.

\section{REFERENCES}

1. Menachery VD, Graham RL, Baric RS. 2017. Jumping species-a mechanism for coronavirus persistence and survival. Curr Opin Virol 23:1-7. https://doi.org/10.1016/j.coviro.2017.01.002.

2. Channappanavar R, Zhao J, Perlman S. 2014. T cell-mediated immune response to respiratory coronaviruses. Immunol Res 59:118-128. https:// doi.org/10.1007/s12026-014-8534-z.

3. Hogue BG, Machamer CE. 2008. Coronavirus structural proteins and virus assembly, p 179-200. In Perlman S, Gallagher T, Snijder EJ(ed), Nidoviruses. ASM Press, Washington, DC.

4. Weisz OA. 2003. Acidification and protein traffic. Int Rev Cytol 226: 259-319. https://doi.org/10.1016/S0074-7696(03)01005-2.

5. Sakaguchi T, Leser GP, Lamb RA. 1996. The ion channel activity of the influenza virus M2 protein affects transport through the Golgi apparatus. J Cell Biol 133:733-747. https://doi.org/10.1083/jcb.133.4.733.

6. Maeda Y, Ide T, Koike M, Uchiyama Y, Kinoshita T. 2008. GPHR is a novel anion channel critical for acidification and functions of the Golgi apparatus. Nat Cell Biol 10:1135-1145. https://doi.org/10.1038/ncb1773.

7. Mollenhauer HH, Morré DJ, Rowe LD. 1990. Alteration of intracellular traffic by monensin; mechanism, specificity and relationship to toxicity. Biochim Biophys Acta 1031:225-246. https://doi.org/10.1016/0304-4157 (90)90008-Z

8. Scott C, Griffin S. 2015. Viroporins: structure, function and potential as antiviral targets. J Gen Virol 96:2000-2027. https://doi.org/10.1099/vir.0 .000201 .

9. Sugrue RJ, Bahadur G, Zambon MC, Hall-Smith M, Douglas AR, Hay AJ. 1990. Specific structural alteration of the influenza haemagglutinin by amantadine. EMBO J 9:3469-3476. https://doi.org/10.1002/j.1460-2075 1990.tb07555x

10. Steinhauer DA, Wharton SA, Skehel JJ, Wiley DC, Hay AJ. 1991. Amantadine selection of a mutant influenza virus containing an acid-stable hemagglutinin glycoprotein: evidence for virus-specific regulation of the $\mathrm{pH}$ of glycoprotein transport vesicles. Proc Natl Acad Sci U S A 88: 11525-11529. https://doi.org/10.1073/pnas.88.24.11525.

11. Ciampor F, Thompson CA, Grambas S, Hay AJ. 1992. Regulation of pH by the M2 protein of influenza A viruses. Virus Res 22:247-258. https://doi .org/10.1016/0168-1702(92)90056-F.

12. Wozniak AL, Griffin S, Rowlands D, Harris M, Yi M, Lemon SM, Weinman SA. 2010. Intracellular proton conductance of the hepatitis $C$ virus p7 protein and its contribution to infectious virus production. PLoS Pathog 6:e1001087. https://doi.org/10.1371/journal.ppat.1001087.

13. Bentham MJ, Foster TL, McCormick C, Griffin S. 2013. Mutations in hepatitis $C$ virus $p 7$ reduce both the egress and infectivity of assembled particles via impaired proton channel function. J Gen Virol 94: 2236-2248. https://doi.org/10.1099/vir.0.054338-0.

14. Machamer CE, Youn S. 2006. The transmembrane domain of the infectious bronchitis virus $E$ protein is required for efficient virus release. Adv Exp Med Biol 581:193-198. https://doi.org/10.1007/978-0-387-33012-9 _33.

15. Ruch TR, Machamer CE. 2011. The hydrophobic domain of infectious bronchitis virus $E$ protein alters the host secretory pathway and is important for release of infectious virus. J Virol 85:675-685. https://doi .org/10.1128/JVI.01570-10.

16. Corse E, Machamer CE. 2002. The cytoplasmic tail of infectious bronchitis virus E protein directs Golgi targeting. J Virol 76:1273-1284. https://doi org/10.1128/JVI.76.3.1273-1284.2002

17. Corse E, Machamer CE. 2003. The cytoplasmic tails of infectious bronchitis virus $E$ and $M$ proteins mediate their interaction. Virology 312: 25-34. https://doi.org/10.1016/S0042-6822(03)00175-2.

18. Ruch TR, Machamer CE. 2012. A single polar residue and distinct membrane topologies impact the function of the infectious bronchitis coronavirus E protein. PLoS Pathog 8:e1002674. https://doi.org/10.1371/ journal.ppat.1002674.

19. Nieto-Torres JL, DeDiego ML, Verdiá-Báguena C, Jimenez-Guardeño JM,
Regla-Nava JA, Fernandez-Delgado R, Castaño-Rodriguez C, Alcaraz A, Torres J, Aguilella VM, Enjuanes L. 2014. Severe acute respiratory syndrome coronavirus envelope protein ion channel activity promotes virus fitness and pathogenesis. PLoS Pathog 10:e1004077. https://doi.org/10 .1371/journal.ppat.1004077.

20. Verdia-Baguena C, Nieto-Torres JL, Alcaraz A, DeDiego ML, Torres J, Aguilella VM, Enjuanes L. 2012. Coronavirus E protein forms ion channels with functionally and structurally-involved membrane lipids. Virology 432:485-494. https://doi.org/10.1016/j.virol.2012.07.005.

21. Westerbeck JW, Machamer CE. 2015. A coronavirus E protein is present in two distinct pools with different effects on assembly and the secretory pathway. J Virol 89:9313-9323. https://doi.org/10.1128/JVI.01237-15.

22. To J, Surya W, Fung TS, Li $Y$, Verdià-Bàguena $C$, Queralt-Martin $M$, Aguilella VM, Liu DX, Torres J. 2017. Channel-inactivating mutations and their revertant mutants in the envelope protein of infectious bronchitis virus. J Virol 91:e02158-16. https://doi.org/10.1128/JVI.02158-16.

23. Westerbeck JW, Machamer CE. 2018. The infectious bronchitis coronavirus envelope protein alters Golgi $\mathrm{pH}$ to protect spike protein and promote release of infectious virus. bioRxiv. https://doi.org/10.1101/ 440628.

24. Yamada Y, Liu DX. 2009. Proteolytic activation of the spike protein at a novel RRRR/S motif is implicated in furin-dependent entry, syncytium formation, and infectivity of coronavirus infectious bronchitis virus in cultured cells. J Virol 83:8744-8758. https://doi.org/10.1128/JVI.00613 $-09$.

25. Parr RL, Collisson EW. 1993. Epitopes on the spike protein of a nephropathogenic strain of infectious bronchitis virus. Arch Virol 133:369-383. https://doi.org/10.1007/BF01313776.

26. Lontok E, Corse E, Machamer CE. 2004. Intracellular targeting signals contribute to localization of coronavirus spike proteins near the virus assembly site. J Virol 78:5913-5922. https://doi.org/10.1128/JVI.78.11 .5913-5922.2004.

27. Miesenböck G, De Angelis DA, Rothman JE. 1998. Visualizing secretion and synaptic transmission with $\mathrm{pH}$-sensitive green fluorescent proteins. Nature 394:192-195. https://doi.org/10.1038/28190.

28. Poschet JF, Boucher JC, Tatterson L, Skidmore J, Van Dyke RW, Deretic V. 2001. Molecular basis for defective glycosylation and Pseudomonas pathogenesis in cystic fibrosis lung. Proc Natl Acad Sci U S A 98: 13972-13977. https://doi.org/10.1073/pnas.241182598.

29. Walls AC, Tortorici MA, Snijder J, Xiong X, Bosch B-J, Rey FA, Veesler D. 2017. Tectonic conformational changes of a coronavirus spike glycoprotein promote membrane fusion. Proc Natl Acad Sci U S A 114: 11157-11162. https://doi.org/10.1073/pnas.1708727114.

30. Shang J, Zheng Y, Yang Y, Liu C, Geng Q, Luo C, Zhang W, Li F. 2018. Cryo-EM structure of infectious bronchitis coronavirus spike protein reveals structural and functional evolution of coronavirus spike proteins. PLoS Pathog 14:e1007009. https://doi.org/10.1371/journal.ppat .1007009 .

31. To J, Torres J. 2018. Beyond channel activity: protein-protein interactions involving viroporins. Subcell Biochem 88:329-377. https://doi.org/10 .1007/978-981-10-8456-0_15.

32. DeDiego ML, Nieto-Torres JL, Jimenez-Guardeño JM, Regla-Nava JA, Castaño-Rodriguez C, Fernandez-Delgado R, Usera F, Enjuanes L. 2014. Coronavirus virulence genes with main focus on SARS-CoV envelope gene. Virus Res 194:124-137. https://doi.org/10.1016/j.virusres.2014.07 .024 .

33. Teoh K-T, Siu Y-L, Chan W-L, Schluter MA, Liu C-J, Peiris JSM, Bruzzone R, Margolis B, Nal B. 2010. The SARS coronavirus E protein interacts with PALS1 and alters tight junction formation and epithelial morphogenesis. Mol Biol Cell 21:3838-3852. https://doi.org/10.1091/mbc.e10-04-0338.

34. Jimenez-Guardeño JM, Nieto-Torres JL, DeDiego ML, Regla-Nava JA, Fernandez-Delgado R, Castaño-Rodriguez C, Enjuanes L. 2014. The PDZbinding motif of severe acute respiratory syndrome coronavirus enve- 
lope protein is a determinant of viral pathogenesis. PLoS Pathog 10: e1004320. https://doi.org/10.1371/journal.ppat.1004320.

35. Lu W, Zheng B-J, Xu K, Schwarz W, Du L, Wong CKL, Chen J, Duan S, Deubel V, Sun B. 2006. Severe acute respiratory syndrome-associated coronavirus 3a protein forms an ion channel and modulates virus release. Proc Natl Acad Sci U S A 103:12540-12545. https://doi.org/10 $.1073 /$ pnas.0605402103.

36. Chen CC, Krüger J, Sramala I, Hsu HJ, Henklein P, Chen YMA, Fischer WB. 2011. ORF8a of SARS-CoV forms an ion channel: experiments and molecular dynamics simulations. Biochim Biophys Acta 1808:572-579. https://doi.org/10.1016/j.bbamem.2010.08.004.

37. Castaño-Rodriguez C, Honrubia JM, Gutiérrez-Álvarez J, DeDiego ML, Nieto-Torres JL, Jimenez-Guardeño JM, Regla-Nava JA, FernandezDelgado R, Verdia-Báguena C, Queralt-Martín M, Kochan G, Perlman S, Aguilella VM, Sola I, Enjuanes L. 2018. Role of severe acute respiratory syndrome coronavirus viroporins $\mathrm{E}, 3 \mathrm{a}$, and $8 \mathrm{a}$ in replication and pathogenesis. mBio 9:e02325-17. https://doi.org/10.1128/mBio.02325-17.

38. Freundt EC, Yu L, Goldsmith CS, Welsh S, Cheng A, Yount B, Liu W, Frieman MB, Buchholz UJ, Screaton GR, Lippincott-Schwartz J, Zaki SR, Xu X-N, Baric RS, Subbarao K, Lenardo MJ. 2010. The open reading frame 3a protein of severe acute respiratory syndrome-associated coronavirus promotes membrane rearrangement and cell death. J Virol 84: 1097-1109. https://doi.org/10.1128/JVI.01662-09.

39. Hitoshi N, Ken-Ichi Y, Jun-Ichi M. 1991. Efficient selection for high- expression transfectants with a novel eukaryotic vector. Gene 108: 193-199. https://doi.org/10.1016/0378-1119(91)90434-D.

40. Neumann $G$, Watanabe $T$, Ito $H$, Watanabe $S$, Goto $H$, Gao $P$, Hughes $M$, Perez DR, Donis R, Hoffmann E, Hobom G, Kawaoka Y, Grantham ML, Stewart SM, Lalime EN, Pekosz A, Ciampor F, Thompson CA, Grambas S, Hay AJ, Steinhauer DA, Wharton SA, Skehel JJ, Wiley DC, Hay AJ. 1991. Tyrosines in the influenza $A$ virus M2 protein cytoplasmic tail are critical for production of infectious virus particles. Proc Natl Acad Sci U S A 22:11525-11529.

41. Sisk JM, Frieman MB, Machamer CE. 2018. Coronavirus S protein-induced fusion is blocked prior to hemifusion by Abl kinase inhibitors. J Gen Virol 99:619-630. https://doi.org/10.1099/jgv.0.001047.

42. Corse E, Machamer CE. 2000. Infectious bronchitis virus E protein is targeted to the Golgi complex and directs release of virus-like particles. J Virol 74:4319-4326. https://doi.org/10.1128/JVI.74.9.4319-4326.2000.

43. Chandran S, Machamer CE. 2008. Acute perturbations in Golgi organization impact de novo sphingomyelin synthesis. Traffic 9:1894-1904. https://doi.org/10.1111/j.1600-0854.2008.00810.x.

44. Zebedee SL, Lamb RA. 1988. Influenza A virus M2 protein: monoclonal antibody restriction of virus growth and detection of $\mathrm{M} 2$ in virions. J Virol 62:2762-2772.

45. Youn S, Leibowitz JL, Collisson EW. 2005. In vitro assembled, recombinant infectious bronchitis viruses demonstrate that the 5 a open reading frame is not essential for replication. Virology 332:206-215. https://doi .org/10.1016/j.virol.2004.10.045. 